\title{
DESASTRES POR FORTES CHUVAS NA REGIÃO DA MATA SUL DE PERNAMBUCO: A IMPORTÂNCIA DA PADRONIZAÇÃO DE PROCEDIMENTOS PELA DEFESA CIVIL ESTADUAL NA ATUAÇÃO JUNTO AOS MUNICÍPIOS
}

Roberto Ryanne Ferraz de Menezes ${ }^{1}$

\section{RESUMO}

O crescimento desordenado das cidades, aliado à ausência de planejamento e de medidas estruturadoras para contenção de riscos, fez com que as ocorrências relacionadas a desastres naturais aumentassem em todo o país. É conhecido também que a Mata Sul de Pernambuco sofre com desastres relacionados a elevadas precipitações pluviométricas, principalmente nos meses de abril, maio, junho e julho, período da quadra chuvosa na região. Nos últimos 20 anos, emergências relacionadas a fortes chuvas deixaram 25 óbitos e somaram prejuízos acima de 46 milhões no Estado. As elevadas precipitações que assolaram a região nos anos de 2010 e 2017, deixaram mais de 135.000 pessoas fora de suas residências, além de um número superior a 30.000 edificações e obras destruídas e danificadas. Sendo assim, a padronização de procedimentos de gestão por parte da Defesa Civil Estadual diante de um cenário calamitoso, é vista como uma ferramenta essencial para a mobilização de recursos e otimização das ações para que os danos e prejuízos ocasionados pelo desastre sejam minimizados na Mata Sul pernambucana.

Palavras-chave: Desastre; Mata Sul de Pernambuco; Precipitação pluviométrica; Procedimentos.

\footnotetext{
${ }^{1}$ Major do Corpo de Bombeiros Militar de Pernambuco e Mestre em Engenharia Civil pela UFPE. E-mail: robertorfmenezes@gmail.com.
} 


\title{
DISASTERS CAUSED BY HEAVY RAIN IN THE REGION OF MATA SUL OF PERNAMBUCO: THE IMPORTANCE OF STANDARDIZATION PROCEDURES BY STATE CIVIL DEFENSE IN OPERATION WITH MUNICIPALITIES
}

\begin{abstract}
The disorderly growth of cities, coupled with the lack of planning and structuring measures to contain risks, caused the raise of occurrences related to natural disasters throughout the country. It is also known that the region of Mata Sul of Pernambuco suffers from disasters related to heavy rainfall, especially in the months of April, May, June and July, the rainy season in the region. In the last 20 years, emergencies related to heavy rains have left 25 deaths and added losses of more than 46 million in the state of Pernambuco. The heavy rainfall that occurred in this region in the years 2010 and 2017, left more than 135,000 people out of their homes, in addition to more than 30,000 buildings and infrastructure works destroyed and damaged. Thus, the standardization of management procedures by the State Civil Defense in the face of a calamitous scenario, is seen as an essential tool to mobilizate resources and optimize the actions to minimize the damages caused by the disaster in the region of Mata Sul of Pernambuco.
\end{abstract}

Keywords: Disaster; Mata Sul of Pernambuco; Rainfall precipitation; Procedures. 


\section{INTRODUÇÃO}

Observa-se, no atual mundo globalizado, que ao passo que há um amplo crescimento dos principais centros urbanos, não se visualiza uma resposta compatível dos governos às suas necessidades. O crescimento desordenado das mesmas trás consequências negativas, principalmente do ponto de vista das ocupações de áreas não propícias à moradia urbana. Por esta ocasião, infelizmente, cada vez mais as populações têm sido submetidas a condições de risco elevado, cujas consequências têm trazido danos muitas vezes irreparáveis. (CASTRO, 2005).

Conforme afirma Freitas et al. (2012), a temática de gestão de desastres é bastante contemporânea, pois ao considerar que nenhum país está completamente imune, independente do patamar de progresso que ele possua, é possível analisar o índice de vulnerabilidade das comunidades a partir do seu nível de desenvolvimento.

Assim, quando aliamos cidades caracterizadas pela urbanização desordenada, cujo preparo para tais eventos têm se mostrado bastante deficitário, com populações completamente desinformadas e alheias aos cenários de risco a que estão submetidas, vemos a importância de se trabalhar a gestão de desastres de uma forma sistemática e objetiva. (GOMES et al., 2016).

Quando situamos de forma mais precisa o objeto deste estudo, verificamos que o estado de Pernambuco se caracteriza pela confluência de duas ameaças naturais, as quais, apesar de antagônicas, têm trazido graves dificuldades, o fenômeno das secas e das enchentes. Esta última é agravada pelas elevadas precipitações pluviométricas aliadas ao crescimento desordenado das cidades, onde a preocupação com a prevenção de desastres tem, na maioria das vezes, ficado em segundo plano. (GOMES et al., 2016). 
O Centro Universitário de Pesquisas e Estudos sobre Desastres (CEPED) de Santa Catarina (2012) revela que os eventos relacionados a inundações bruscas e graduais são uma das maiores causas de ocorrências de desastres naturais no país.

Esses acontecimentos representam um motivo de crescente inquietação, pois a vulnerabilidade potencializada pela incerteza da magnitude das ameaças naturais sinaliza para um futuro preocupante. No caso dos desastres ocasionados por enchentes, uma série de interrupções no funcionamento de uma comunidade, com impactos sobre as pessoas, bens, economia e meio ambiente, são gerados. (SILVA et al., 2012).

Em Pernambuco, as enchentes, e suas consequências danosas, sempre estiveram em destaque no âmbito nacional, mas foi no ano de 2010 que os holofotes se voltaram para o Estado, em virtude da ocorrência de uma destruição sem precedentes, principalmente na região da Zona da Mata Sul, área que acabou reunindo os danos mais consideráveis. (PERNAMBUCO, 2019).

Da mesma forma, em 2017 o estado de Pernambuco foi novamente assolado por um desastre idêntico, requerendo do poder público ações ligadas à Defesa Civil e todos os demais órgãos ligados à gestão de desastres, abrangendo desde as ações de prevenção, mitigação e preparação (monitoramento dos riscos, emissão de alertas e conscientização das populações em áreas vulneráveis), ações de resposta (resgate das vítimas e assistência humanitária para os atingidos) até ações de recuperação (restabelecimento e reconstrução das áreas atingidas, com o intento de retorno à normalidade).

Com mais de 16.000 desabrigados e 118.000 desalojados, as chuvas de 2010 e 2017, as quais afetaram a Zona da Mata Sul de Pernambuco, fazemnos refletir sobre quais medidas estão sendo adotadas pelos órgãos públicos, em especial a Defesa Civil do Estado, para minimizar as perdas, isto é, 
ferramentas de gestão que visem oferecer uma resposta rápida e simultânea dos órgãos governamentais. (BRASIL, 2020).

Para Amorim e Silva (2016), se todos os órgãos e gestores públicos compreendessem a importância de se ter uma gestão integrada e padronizada, o sistema de defesa civil proporcionaria, além do socorro e ajuda humanitária à população atingida, o progressivo restabelecimento da normalidade de forma célere.

Segundo Castro (2005), o envolvimento de diversos órgãos da sociedade também se faz necessário no rol de obrigações e atribuições durante as ações de resposta, devendo ser coordenadas e planejadas para que as tarefas específicas contemplem intervenções oportunas para se evitar ou minimizar as consequências de um desastre.

Neste viés, a padronização de procedimentos de gestão para resposta a enchentes na Mata Sul de Pernambuco surge como uma forma de nortear a conduta no gerenciamento de desastres e, consequentemente, trazer agilidade nas ações quanto a ocorrências relacionadas a elevados índices de precipitação pluviométrica. Para tanto, é de fundamental importância que aliado às normas e demais ferramentas teórico-legislativas, esse planejamento determine as atribuições de cada órgão ou setor envolvido, gerando uma conscientização de suas obrigações, a fim de priorizar a celeridade e objetividade de tais condutas nas ações de resposta.

\section{MÉTODO}

Utiliza-se como método para aferição e apresentação dos dados nesta pesquisa, a tabulação e interpretação dos dados, derivante dos atendimentos realizados pela Defesa Civil de Pernambuco na Zona da Mata Sul do Estado, bem como a revisão bibliográfica quanto ao tema em análise.

Assim a pesquisa alicerça-se na lógica hipotética dedutiva proposta Lakatos e Marconi (2011), quando sugerem que a hipótese de pesquisa deve 
coletar subsídios para a comprovação, partindo da premissa de que é possível o estabelecimento de relações entre a importância da padronização de procedimentos de gestão e os desastres ocorridos.

Além disso, foram utilizados como aliados na análise dos dados, a base de dados demográficos do Instituto Brasileiro de Geografia e Estatística.

\section{DESENVOLVIMENTO E RESULTADOS}

\subsection{O Sistema Nacional de Proteção e Defesa Civil}

Considerando o estado brasileiro em sua concepção continental, observamos que a prática de qualquer política pública com âmbito nacional demanda dos diversos entes um esforço hercúleo, o qual muitas vezes suplanta os objetivos primordiais da medida, denotando muito mais num desafio intransponível do que uma solução.

Assim, trazendo à tona a realidade brasileira, era observado que, diferente da concepção atual, a defesa civil, surgida em 1942, possuía uma finalidade que a atraía muito mais à resposta de ataques militares, cujo objetivo era possibilitar um retorno à normalidade com a maior brevidade possível. Porém, somente na década de 60 sua concepção mudaria, passando a obter um caráter de defesa comunitária, alcançada através da realização de ações preventivas e de resposta à desastres naturais, mais precisamente, enchentes e deslizamentos. (SANTA CATARINA, 2014).

Tal situação perdurou até meados da década de 90 , quando em atendimento à Resolução 44/236 foi elaborado o Plano Nacional de Redução de Desastres, o qual estabelecia metas a serem alcançadas até o ano 2000, dentre elas destacavam-se: a reestruturação da Secretaria Nacional de Defesa Civil no âmbito nacional, a elaboração de manuais técnicos de defesa civil e a criação da codificação de desastres. (NETO, 2007).

Com o passar dos anos foi-se observando que houve uma maior preocupação por parte do Estado com as vulnerabilidades paulatinamente mais 
complexas, aliadas às ameaças cada vez mais comuns, as quais denotaram em cenários de riscos cada vez maiores, e que demandavam imensas dificuldades para a intervenção do poder público. (CASTRO, 2005).

Neste viés, Pozzer, Cohen e Costa (2014, p. 4) preceituam o seguinte:

De acordo com a Estratégia Internacional para Redução de Desastres / Organização das Nações Unidas (EIRD/ONU, 2007), mais de 200 milhões de pessoas são afetadas todos os anos pelos desastres naturais. Justifica-se, por isso, a urgência de se procurar a utilização de uma estratégia de atuação em situações de desastres naturais que seja capaz de reduzir e mitigar as consequências advindas desses fenômenos, de maneira a proteger a sociedade, preveni-la e prever seus riscos para, dessa forma, fortalecer a capacidade de preparação e resposta dos países frente a essas situações.

Baseada justamente neste entendimento, a própria Constituição Federal (1988) em seu Art. 21, XVIII, assevera que: "a União deve planejar e promover a defesa permanente contra as calamidades públicas, especialmente a seca e inundações."

Para tanto, foi promulgada no ano de 2012 a Lei o 12.608, que institui a Política Nacional de Proteção e Defesa Civil - PNPDEC e dispõe sobre o Sistema Nacional de Proteção e Defesa Civil - SINPDEC assim como o Conselho Nacional de Proteção e Defesa Civil - CONPDEC. (BRASIL, 2012).

Assim, a partir da instituição da PNPDEC e do SINPDEC foi possível estabelecer quais os objetivos, quais as competências de cada ente federativo, e a quais diretrizes a atuação dos órgãos de defesa civil deverão estar submetidos quando da sua ação. (BRASIL, 2012).

Há de se ressaltar que de forma proposital o legislador fez questão de lançar mão de forma repetitiva de palavras como: integração, ação sistematizada, articulação, apoio, dentre outras com significado similar, cujo desiderato foi demonstrar a extrema necessidade de que as ações sejam 
realizadas com a união de esforços dos entes federados, possibilitando uma maior probabilidade de alcance dos objetivos ora traçados. (BACK, 2016).

É neste viés que a Defesa Civil de Pernambuco, de forma integrada com a União e os Municípios, vem buscando construir, principalmente em situações emergenciais, soluções eficazes para minimizar os efeitos causados pelos desastre.

\subsection{Delimitação conceitual}

De acordo com Castro (2004), há diversas conceituações que poderão ser empregadas a fim de se veicular uma informação relacionada a elevadas precipitações pluviométricas, entre as principais, destacam-se: inundação, alagamento e enxurrada.

De acordo com a Codificação Brasileira de Desastres - COBRADE (2016, Anexo V), esses conceitos são definidos como:

a) Inundação - Submersão de áreas fora dos limites normais de um curso de água em zonas que normalmente não se encontram submersas. O transbordamento ocorre de modo gradual, geralmente ocasionado por chuvas prolongadas em áreas de planície.

b) Alagamento - Extrapolação da capacidade de escoamento de sistemas de drenagem urbana e consequente acúmulo de água em ruas, calçadas ou outras infraestruturas urbanas, em decorrência de precipitações intensas.

c) Enxurrada - Escoamento superficial de alta velocidade e energia, provocado por chuvas intensas e concentradas, normalmente em pequenas bacias de relevo acidentado. Caracterizada pela elevação súbita das vazões de determinada drenagem e transbordamento brusco da calha fluvial. Apresenta grande poder destrutivo.

Dentre esses diversos conceitos, há aqueles que melhor se enquadram diante dos cenários apresentados. No caso das fortes chuvas que assolaram a 
região da Mata Sul pernambucana nos anos de 2010 e 2017, foi possível presenciar todos esses fenômenos.

É importante destacar também que chuvas consideradas "fortes", de acordo com a Agência Pernambucana de Águas e Clima (APAC, 2020), são aquelas em que o registro de precipitação pluviométrica foi acima de $40 \mathrm{~mm}$.

Outros conceitos bastante difundidos durante a gestão de desastres oriundos de elevadas precipitações pluviométricas e estabelecidos pelo Manual Técnico de Defesa Civil de Pernambuco $(2019$, p. 3) são:

a) Desabrigado - São as pessoa cujas habitações foram destruídas ou danificadas por desastres, ou estão localizadas em áreas de risco iminente de destruição, e que necessitam de abrigos temporários para serem alojadas.

b) Desalojado - São as pessoa cujas habitações foram danificadas ou destruídas, mas que não, necessariamente, precisam de abrigos temporários.

Por fim, dois outros termos associados a todos os tipos de desastres são:

a) Dano - Resultado das perdas humanas, materiais ou ambientais infligidas às pessoas, comunidades, instituições, instalações e aos ecossistemas, como consequência de um desastre. Medida que define a severidade ou intensidade da lesão resultante de um acidente ou evento adverso.

b) Prejuízo - Medida de perda relacionada com o valor econômico, social e patrimonial de um determinado bem, em circunstâncias de desastre. (PERNAMBUCO, 2019, p.5)

De acordo com o Módulo 1 do Manual de Capacitação para utilização do S2ID (2020) os prejuízos são classificados em prejuízos econômicos públicos e privados. Os prejuízos econômicos públicos são aqueles decorrentes da interrupção ou comprometimento de algum serviço essencial 
(saúde, educação, segurança etc.), e sua medida se dá pelos custos extras que o poder público tem que arcar para substituir ou ampliar algum serviço temporariamente ou mesmo pela interrupção da arrecadação pela não prestação de algum serviço. Já os prejuízos privados, por sua vez, são classificados de acordo com os principais setores da economia que foram afetados. São perdas que atingiram empresas ou pessoas que atuam na agricultura, pecuária, indústria, comércio e serviços, que poderão ou não ser recuperadas.

Essas conceituações, segundo Marcondes (2003), são primordiais quando se busca verificar o número de afetados, os danos relacionados e os prejuízos ocasionados em eventos oriundos por fortes chuvas.

\subsection{A Mata Sul de Pernambuco e suas nuances}

Formado por 24 municípios, a Mata Sul pernambucana conta com uma população estimada de 792.673 habitantes localizados em $5 \%$ de todo território estadual. (IBGE, 2020).

Marcado pela presença de desastres relacionados a elevadas precipitações, a Mata Sul tem em seu histórico fortes chuvas que atingiram severamente as comunidades residentes principalmente em áreas vulneráveis, como nos acontecimentos dos anos de 2010 e 2017. (PERNAMBUCO, 2018)

Do ponto de vista climático, a região é caracterizada por apresentar clima úmido com chuvas acima da média histórica de todo o Estado, chegando a atingir, em alguns municípios, cotas superiores a $2.000 \mathrm{~mm}$ anuais. (AMORIM e SILVA, 2016).

De acordo com o Manual de Procedimentos da Operação Inverno da Defesa Civil de Pernambuco (2020), os meses com maior probabilidade de apresentarem elevadas precipitações pluviométricas e, consequentemente, ocasionarem danos e prejuízos relacionados a fortes chuvas, são os de junho e julho, os quais chegam a registrar, muitas vezes, chuvas acima de $400 \mathrm{~mm}$ no mês. 
Gráfico 1: Representação da vigência da Operação Inverno para a Região Metropolitana do Recife, Zona da Mata e Agreste do Estado em função do acúmulo de precipitação. Gráfico da cidade do Recife.

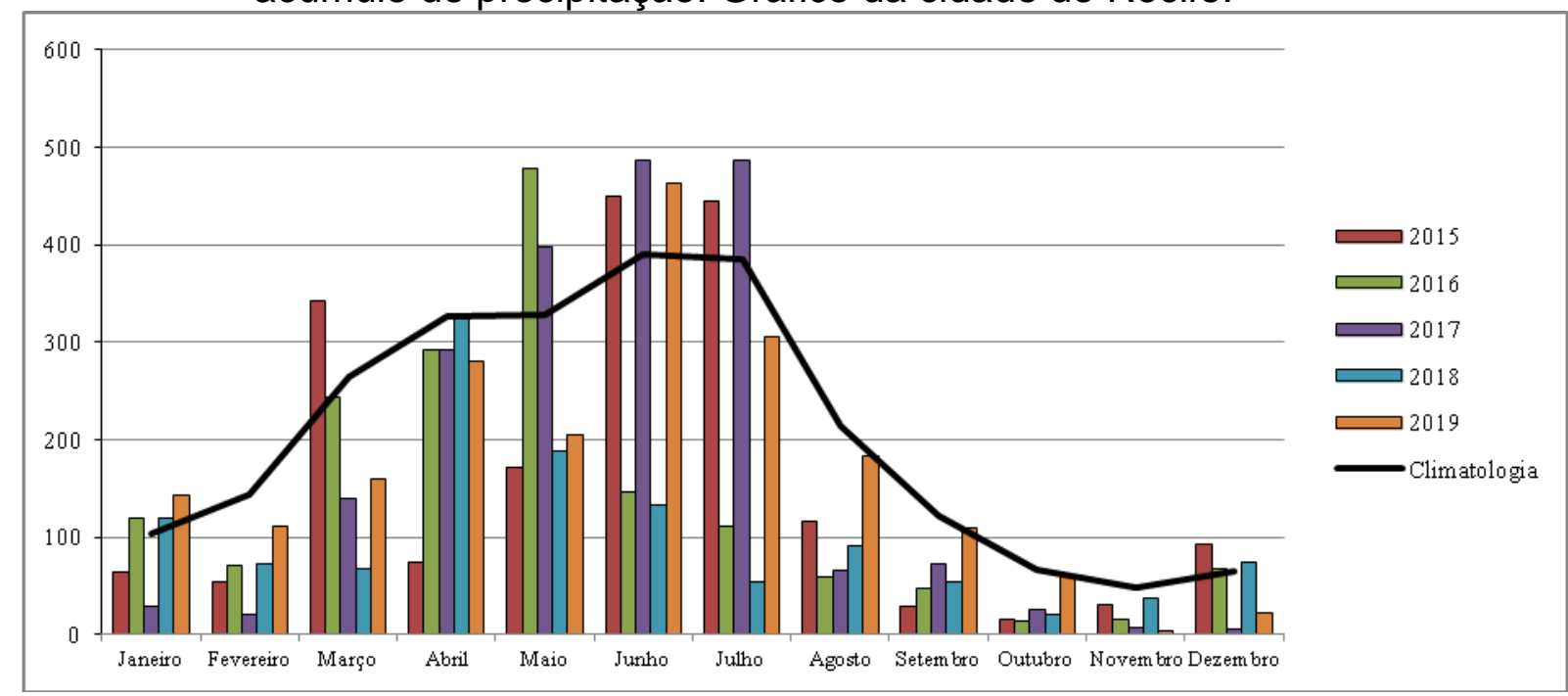

Fonte: Dados da Pesquisa. Com base no Manual de Procedimentos da Operação Inverno 2020 da SEDEC-PE.

Sabe-se que a magnitude e a frequência de ocorrências por fortes chuvas ocorrem em função de fatores como: intensidade e distribuição da precipitação, taxa de infiltração de água no solo, grau de saturação do solo e características morfométricas e morfológicas da bacia de drenagem. (SANTA CATARINA, 2012).

Para Silva et al. (2012), o modelo de urbanização mostra que estes fenômenos naturais têm se intensificado devido às alterações antrópicas, como a retificação e assoreamento de cursos d'água. Além disso, a ocupação de planícies de inundação e impermeabilizações ao longo de vertentes produzem resultados calamitosos.

De acordo com o Sistema Integrado de Informações sobre Desastres (S2ID), plataforma do Governo Federal, entre os anos de 2000 a 2019 foram registrados, pelos municípios da Zona da Mata de Pernambuco, 99 ocorrências por enxurrada, sendo que destes, 87 aconteceram na Mata Sul, o que 
Revista Científica do Corpo de Bombeiros Militar de Pernambuco

Artigo Publicado no Vol.07 N.18 - Edição Jan a Jun 2021 - ISSN 2359-4829

Versão on-line disponível em: http://www.revistaflammae.com

representa, aproximadamente, $88 \%$ do valor total de registros na Zona da Mata.

Figura 1: Ocorrências de enxurrada registradas em Pernambuco entre os anos de 2000 e 2019.

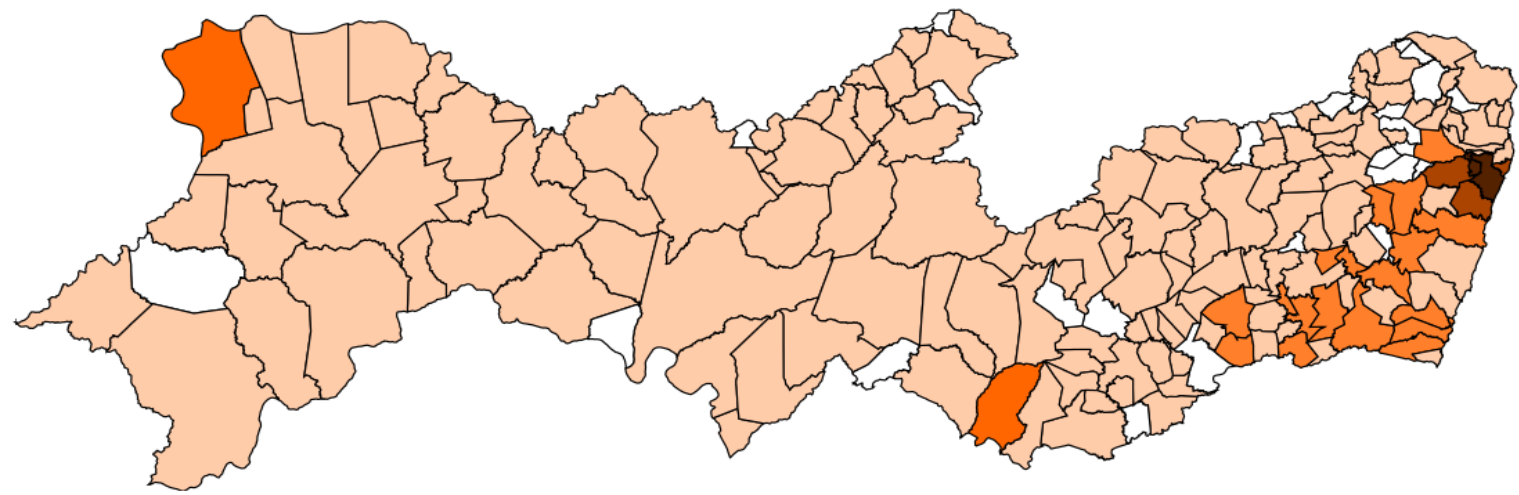
Nenhuma ocorrência
De 1 a 4 ocorrências
De 5 a 8 ocorrências
De 9 a 12 ocorrências
De 13 a 16 ocorrências

Fonte: Dados da Pesquisa. Com base no Relatório Estatístico da Gerência Operacional da SEDEC-PE (2020).

Das 87 ocorrências de enxurrada que aconteceram na Zona da Mata Sul entre os anos de 2000 e 2019, 80\% aconteceram na quadra chuvosa (compreendido entre os meses de abril a julho), como visto a seguir.

Gráfico 2: Relação do número de ocorrências de enxurradas na Mata Sul de Pernambuco por mês, entre os anos de 2000 e 2019.

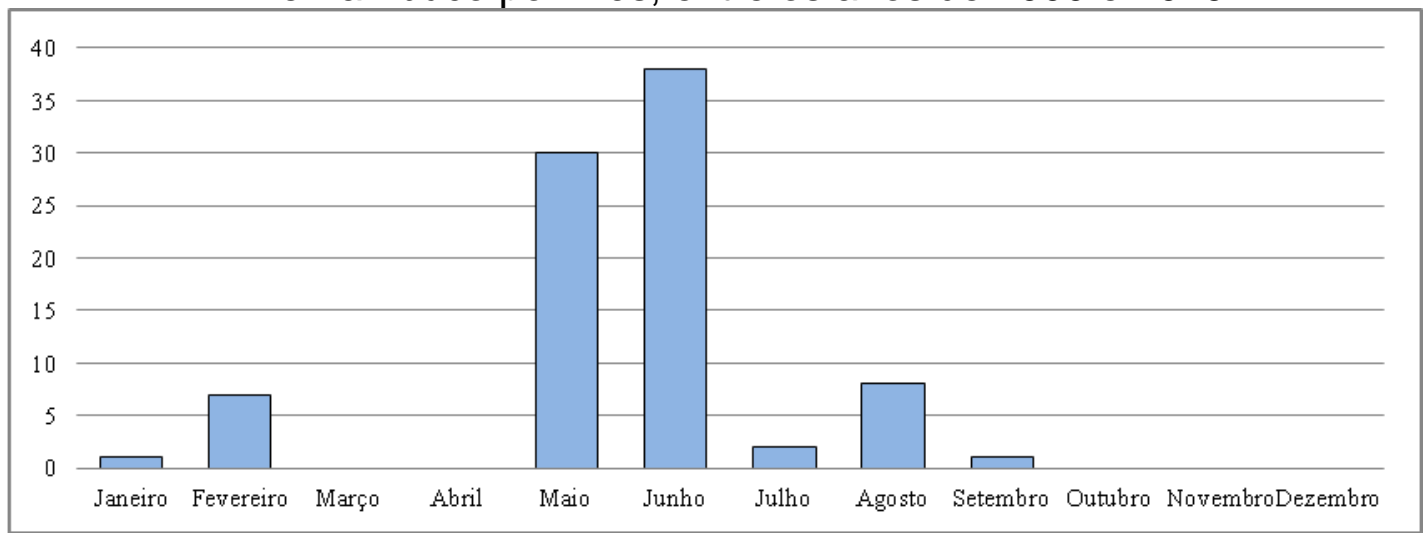


É importante frisar que embora o município atingido por fortes chuvas venha a presenciar, em alguns casos, dois ou três tipos de desastres relacionados a elevadas precipitações (enxurrada, inundação e/ou alagamento), há uma orientação, por parte da Defesa Civil Estadual, do município tipificar a ocorrência com base na que traga maiores impactos, como é o caso dos desastres por enxurradas. Em virtude disso, o número de ocorrências existentes na plataforma S2ID relacionado a elevadas precipitações na Mata Sul, entre os anos de 2000 a 2019, somam 96, sendo 07 por inundações, 02 por alagamentos e 87 por enxurradas, o que corrobora para que esta última se destaque em relação às demais.

Fazendo-se uma análise do gráfico apresentado, é fácil constatar que os meses de maio e junho foram os que mais registraram ocorrências, visto estarem dentro dos meses correspondentes à quadra chuvosa na região.

Outrossim, realizando uma comparação com o somatório das precipitações pluviométrica registradas pelos municípios da Mata Sul do Estado nos últimos 5 anos, entre 2015 e 2019, é possível ratificar a probabilidade de que este tipo de desastre venha a ter seu nascedouro durante os meses da quadra chuvosa, o que favorece, contudo, as Defesa Civis e órgãos operativos desenvolverem planejamentos voltados para este período.

Quadro 1: Precipitação pluviométrica acumulada (em milímetros) dos municípios da Mata Sul de Pernambuco, entre os anos de 2015 e 2019, tendo por base um pluviômetro por município.

\begin{tabular}{|c|c|c|c|c|c|c|c|c|c|c|c|c|c|}
\hline ANO & JAN & FEV & MAR & ABR & MAIO & JUN & JUL & AGO & SET & OUT & NOV & DEZ & TOTAL \\
\hline $\begin{array}{c}\text { Climatologi } \\
\text { a }\end{array}$ & 1.602 & 1.826 & 3.002 & 3.662 & 4.506 & 5.491 & 4.912 & 2.809 & 1.518 & 704 & 621 & 881 & $\mathbf{3 1 . 5 3 4}$ \\
\hline $\mathbf{2 0 1 5}$ & 851 & 1.034 & 3.101 & 605 & 2.995 & 6.883 & 7.401 & 1.882 & 800 & 511 & 117 & 2.038 & $\mathbf{2 8 . 2 1 8}$ \\
$\mathbf{2 0 1 6}$ & 2.402 & 1.908 & 3.815 & 4.577 & 4.819 & 3.115 & 2.133 & 1.032 & 1.026 & 567 & 392 & 431 & $\mathbf{2 6 . 2 1 7}$ \\
$\mathbf{2 0 1 7}$ & 704 & 514 & 1.077 & 4.632 & 11.665 & 7.744 & 8.655 & 2.455 & 2.882 & 1.094 & 392 & 1.521 & $\mathbf{4 3 . 3 3 4}$ \\
$\mathbf{2 0 1 8}$ & 3.202 & 3.603 & 3.612 & 7.824 & 4.363 & 1.998 & 2.181 & 966 & 663 & 120 & 1.076 & 1.096 & $\mathbf{3 0 . 7 0 3}$ \\
$\mathbf{2 0 1 9}$ & 2.982 & 2.208 & 3.156 & 3.238 & 3.211 & 6.642 & 7.980 & 4.154 & 1.724 & 590 & 50 & 580 & $\mathbf{3 6 . 5 1 3}$ \\
\hline TOTAL & $\mathbf{1 0 . 1 4}$ & $\mathbf{9 . 2 6 6}$ & $\mathbf{1 4 . 7 6}$ & $\mathbf{2 0 . 8 7 6}$ & $\mathbf{2 7 . 0 5 3}$ & $\mathbf{2 6 . 3 8 2}$ & $\mathbf{2 8 . 3 5 0}$ & $\mathbf{1 0 . 4 8 8}$ & $\mathbf{7 . 0 9 4}$ & $\mathbf{2 . 8 8 2}$ & $\mathbf{2 . 0 2 8}$ & $\mathbf{5 . 6 6 5}$ & \\
\hline
\end{tabular}

Fonte: Relatório Estatístico da Gerência Operacional da SEDEC-PE (2020). 
Revista Científica do Corpo de Bombeiros Militar de Pernambuco

Artigo Publicado no Vol.07 N.18 - Edição Jan a Jun 2021 - ISSN 2359-4829

Versão on-line disponível em: $\underline{\text { http://www.revistaflammae.com }}$

Gráfico 3: Precipitação pluviométrica acumulada (em milímetros) dos municípios da Mata Sul de Pernambuco, entre os anos de 2015 e 2019, tendo por base um pluviômetro por município.

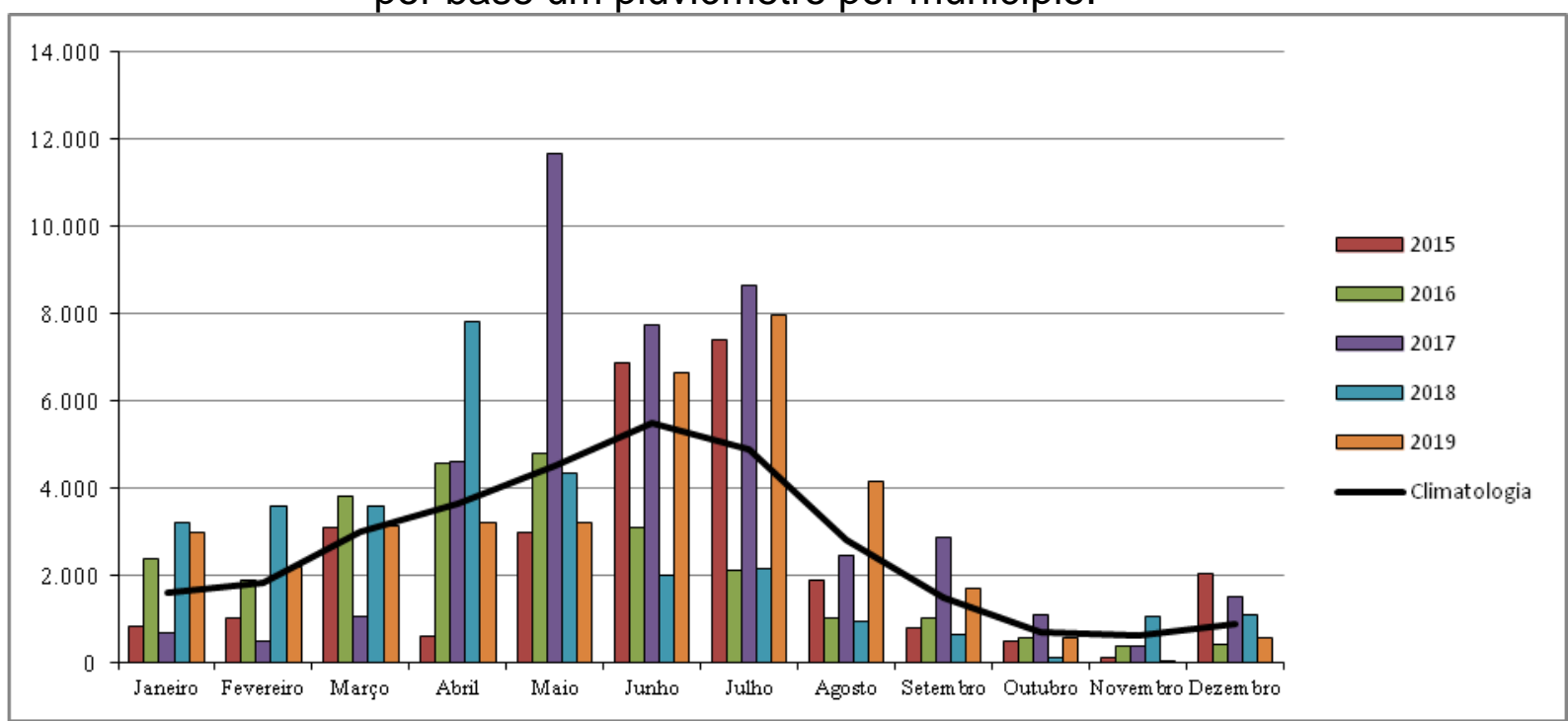

Fonte: Relatório Estatístico da Gerência Operacional da SEDEC-PE (2020).

Quadro 2: Precipitação pluviométrica acumulada (em milímetros) de todos os municípios de Pernambuco, entre os anos de 2015 e 2019, tendo por base um pluviômetro por município.

\begin{tabular}{|c|c|c|c|c|c|c|c|c|c|c|c|c|c|}
\hline ANO & JAN & FEV & MAR & ABR & MAIO & JUN & JUL & AGO & SET & OUT & NOV & DEZ & TOTAL \\
\hline $\begin{array}{c}\text { Climatologi } \\
\mathbf{a}\end{array}$ & $\begin{array}{c}11.67 \\
6\end{array}$ & $\begin{array}{c}14.53 \\
3\end{array}$ & $\begin{array}{c}22.54 \\
3\end{array}$ & $\begin{array}{c}23.57 \\
0\end{array}$ & 22.310 & $\begin{array}{c}24.13 \\
9\end{array}$ & $\begin{array}{c}21.93 \\
5\end{array}$ & $\begin{array}{c}11.93 \\
4\end{array}$ & 6.664 & 3.800 & 4.251 & 6.995 & 174.351 \\
\hline 2015 & 3.613 & 7.977 & $\begin{array}{c}19.83 \\
6\end{array}$ & 6.253 & 11.534 & $\begin{array}{c}25.24 \\
5\end{array}$ & $\begin{array}{c}30.72 \\
1\end{array}$ & 7.069 & 2.370 & 1.536 & 549 & $\begin{array}{c}10.45 \\
0\end{array}$ & 127.153 \\
\hline 2016 & $\begin{array}{c}23.53 \\
9\end{array}$ & $\begin{array}{c}10.09 \\
0\end{array}$ & $\begin{array}{c}17.06 \\
6\end{array}$ & $\begin{array}{c}16.37 \\
0\end{array}$ & 25.711 & $\begin{array}{c}10.71 \\
8\end{array}$ & 6.858 & 3.489 & 3.269 & 1.551 & 1.214 & 3.786 & 123.660 \\
\hline 2017 & 3.804 & 5.545 & $\begin{array}{c}11.36 \\
8\end{array}$ & $\begin{array}{c}21.19 \\
2\end{array}$ & 36.115 & $\begin{array}{c}28.46 \\
7\end{array}$ & $\begin{array}{c}36.02 \\
6\end{array}$ & 9.047 & $\begin{array}{c}10.09 \\
0\end{array}$ & 3.292 & 1.708 & 4.609 & 171.263 \\
\hline 2018 & $\begin{array}{c}13.63 \\
0\end{array}$ & $\begin{array}{c}23.38 \\
6\end{array}$ & $\begin{array}{c}19.62 \\
8\end{array}$ & $\begin{array}{c}38.42 \\
1\end{array}$ & 17.092 & 8.372 & 7.444 & 3.122 & 2.238 & 2.093 & 4.379 & $\begin{array}{c}11.39 \\
2\end{array}$ & 151.196 \\
\hline 2019 & 9.527 & $\begin{array}{c}17.17 \\
9 \\
\end{array}$ & $\begin{array}{c}26.55 \\
6 \\
\end{array}$ & $\begin{array}{c}18.09 \\
2 \\
\end{array}$ & 13.240 & $\begin{array}{c}27.26 \\
2 \\
\end{array}$ & $\begin{array}{c}31.59 \\
4 \\
\end{array}$ & $\begin{array}{c}15.36 \\
9 \\
\end{array}$ & 5.824 & 2.524 & 2.429 & 1.876 & 171.471 \\
\hline TOTAL & $\begin{array}{c}54.11 \\
2\end{array}$ & $\begin{array}{c}64.17 \\
8\end{array}$ & $\begin{array}{c}94.45 \\
4\end{array}$ & 100.328 & 103.691 & 100.064 & 112.642 & 38.095 & $\begin{array}{c}23.79 \\
0\end{array}$ & $\begin{array}{c}10.99 \\
7\end{array}$ & $\begin{array}{c}10.28 \\
0\end{array}$ & $\begin{array}{c}32.11 \\
3\end{array}$ & \\
\hline
\end{tabular}

Fonte: Relatório Estatístico da Gerência Operacional da SEDEC-PE (2020). 
Revista Científica do Corpo de Bombeiros Militar de Pernambuco

Artigo Publicado no Vol.07 N.18 - Edição Jan a Jun 2021 - ISSN 2359-4829

Versão on-line disponível em: http://www.revistaflammae.com

Gráfico 4: Precipitação pluviométrica acumulada (em milímetros) de todos os municípios de Pernambuco, entre os anos de 2015 e 2019, tendo por base um pluviômetro por município.

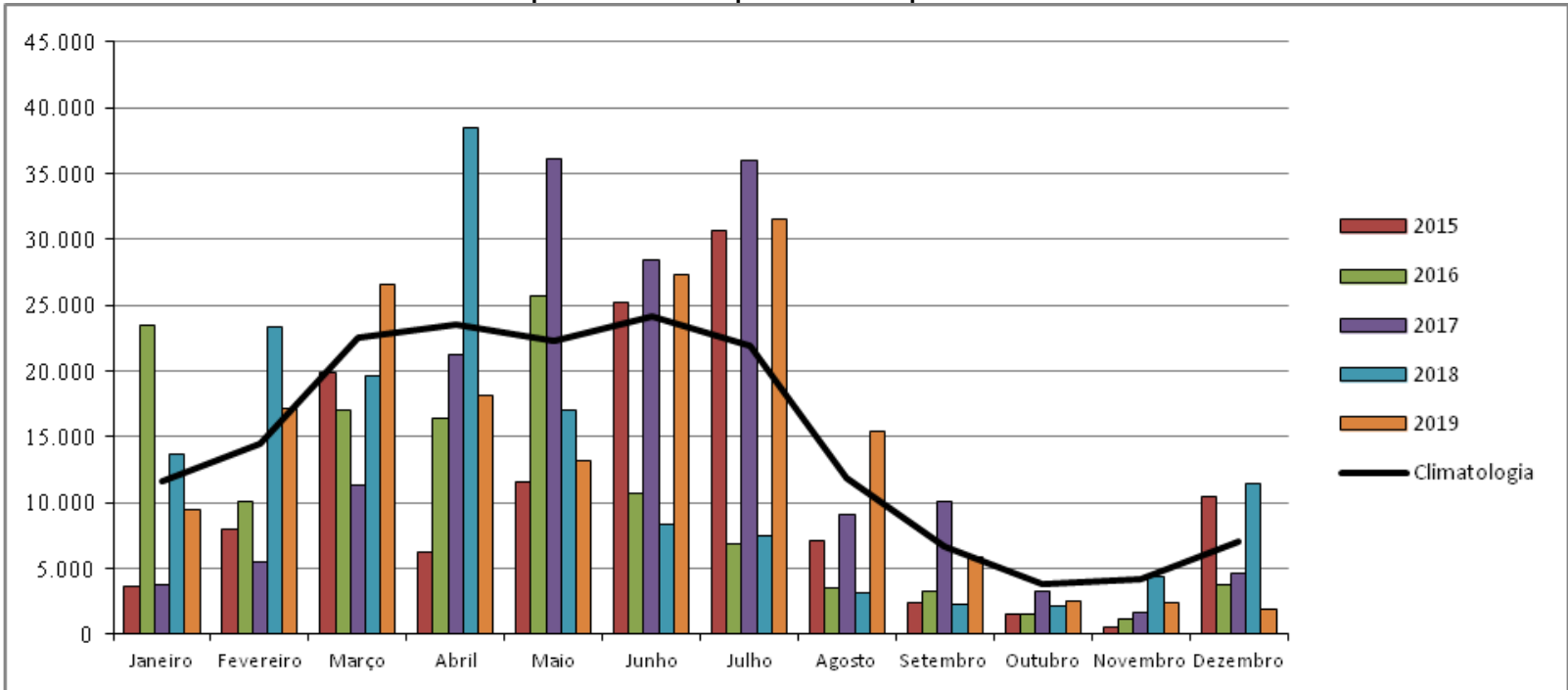

Fonte: Relatório Estatístico da Gerência Operacional da SEDEC-PE (2020).

É de bom alvitre destacar que o acumulado de precipitação mostrado anteriormente por meio de tabelas e gráficos são relativos ao somatório feito com base em um único pluviômetro escolhido por município, visto que há municípios que possuem mais de um pluviômetro instalado.

É notório, quando lançamos um olhar mais acurado para o acumulado de precipitação nos municípios da Mata Sul, que durante os meses de abril a julho, quadra chuvosa da região, foi registrado uma média de $20.532 \mathrm{~mm}$ de chuvas para o período a cada ano, o que corresponde a $62 \%$ do previsto para todos os meses.

Quando levado em consideração todo o Estado, é verificado que aproximadamente $25 \%$ das chuvas que ocorrem no período de abril a julho se concentram na Mata Sul, ou seja, em apenas $5 \%$ do território pernambucano. Já quando comparamos a média de chuvas por ano da região em relação com os 184 municípios mais o arquipélago de Fernando de Noronha, que compõem o Estado de Pernambuco, aproximadamente $22 \%$ das chuvas se concentram na Mata Sul. 
Revista Científica do Corpo de Bombeiros Militar de Pernambuco

Artigo Publicado no Vol.07 N.18 - Edição Jan a Jun 2021 - ISSN 2359-4829

Versão on-line disponível em: http://www.revistaflammae.com

Atrelado a elevadas precipitações, danos e prejuízos são ocasionados principalmente quando as águas dessas chuvas surgem com elevado poder de destruição, como no caso das enxurradas.

$\mathrm{Na}$ tabela a seguir estão demonstrados alguns danos humanos e materiais decorrentes de eventos ocasionados por enxurradas nos municípios da Mata Sul de Pernambuco a partir do ano de 2000, e que foram computados por meio da plataforma S2ID do Governo Federal.

Quadro 3: Registro de danos humanos e materiais, de 2000 a 2019, em ocorrências por enxurradas na Mata Sul de Pernambuco.

\begin{tabular}{|c|c|c|c|c|c|}
\hline Ano & Óbitos & Desabrigados & Desalojados & $\begin{array}{l}\text { Outros } \\
\text { afetados }\end{array}$ & $\begin{array}{c}\text { Edificações e obras } \\
\text { destruídas / } \\
\text { danificadas }\end{array}$ \\
\hline 2000 & 10 & 6.597 & 11.117 & 1.209 & 8.731 \\
\hline 2001 & - & - & - & - & - \\
\hline 2002 & - & - & - & - & 50 \\
\hline 2003 & - & - & 70 & - & 09 \\
\hline 2004 & - & 1.064 & 654 & 4.798 & 627 \\
\hline 2005 & 04 & 3.017 & 16.903 & 14.264 & 4.948 \\
\hline 2006 & - & - & - & - & - \\
\hline 2007 & - & - & - & - & - \\
\hline 2008 & - & - & - & - & - \\
\hline 2009 & 02 & 63 & 287 & 04 & 15 \\
\hline 2010 & 08 & 14.094 & 79.462 & 8.071 & 27.594 \\
\hline 2011 & - & - & 392 & - & 112 \\
\hline 2012 & - & - & - & - & - \\
\hline 2013 & - & - & - & - & - \\
\hline 2014 & - & - & - & - & - \\
\hline 2015 & - & - & - & - & - \\
\hline 2016 & - & - & - & - & - \\
\hline 2017 & 1 & 2.739 & 39.122 & 665.264 & 3.313 \\
\hline 2018 & - & - & 603 & 2.543 & 165 \\
\hline 2019 & - & - & - & - & - \\
\hline TOTAL & 25 & 27.574 & 148.610 & 696.153 & 45.564 \\
\hline
\end{tabular}

Fonte: Sistema Integrado de Informações sobre Desastre - S2ID (2020). 
Afora o número elevado de danos humanos e materiais ocasionados por esses desastres, os valores relacionados aos prejuízos econômicos públicos e privados também se destacam. De acordo com a plataforma S2ID do Governo Federal (BRASIL, 2020), no desastre ocorrido entre os meses de maio e junho de 2017 nos municípios da Mata Sul de Pernambuco foram relatados prejuízos econômicos públicos de $R \$ 34.033 .832,56$, e prejuízos econômicos privados de $R \$ 12.653 .150,00$, o que corrobora para um olhar atencioso por parte dos órgãos de resposta em virtude de números vultosos.

\subsection{A importância do planejamento nos desastres}

De acordo com o dicionário Michaelis (2020), a palavra planejamento possui o seguinte significado:
1. Ato de planejar.
2. Organização de uma tarefa com a utilização de métodos apropriados.
3. Determinação de ações para atingir as metas estipuladas por uma empresa, órgão do governo etc.

Neste sentido, para o alcance da eficácia em qualquer objetivo, é de fundamental importância que se priorize o planejamento, sobretudo quando nos referimos ao uso de recursos públicos, onde deve-se ter como baliza sempre o desiderato de se atender ao interesse público, o qual, com o passar dos tempos, veio tomando contornos cada vez mais complexos no que concerne à sua definição. (CASTRO, 2005).

Há de se ressaltar que, em se seguindo o caminho correto das ações, o planejamento deve ser prévio às ações efetivas, ou seja, nas atividades de defesa civil, ocorrendo anteriormente à ocorrência dos desastres, ou mesmo, quando em situações de desastres com caráter recorrente, no período de normalidade, considerando todas as características e histórico dos eventos já ocorridos. (SHADECK et al., 2013). 
Assim, considerando as fases da defesa civil, a Defesa Civil Estadual deve trabalhar prioritariamente de forma prévia ao desastre, na construção de planos e procedimentos, os quais planificarão as atribuições de cada ator que estará envolvido no cenário a que se destina (FIALHO, 2013).

\subsection{A padronização de procedimentos de gestão frente aos desastres}

Diante da possibilidade do surgimento de fortes chuvas, com destaque para a Mata Sul de Pernambuco, a necessidade da padronização de procedimentos de gestão surge a partir de determinadas hipóteses de situações oriundas dos desastres que podem gerar atitudes e respostas diferentes por parte dos gestores estaduais de defesa civil nos municípios.

Documentos como Procedimentos Operacionais Padrão (POP), Ordem de Operações, manuais, legislações, entre outros, devem ser elaborados para serem adotados pelos envolvidos na resposta ao desastre, padronizando aspectos relacionados ao monitoramento, alerta, alarme e resposta, este último, incluindo as ações de socorro, ajuda humanitária e reabilitação de cenários, a fim de reduzir os danos decorrentes da adversidade. (SÃO PAULO, 2011).

A padronização de procedimentos se torna uma ferramenta primordial para minimizar ou até mesmo evitar distorções de entendimento por parte dos integrantes da Defesa Civil Estadual durante a gestão do sinistro. Os efeitos da não padronização podem acarretar em uma análise pessoal, por parte do gestor estadual, levando ao excesso ou até mesmo ausência no emprego de medidas e meios de resposta frente aos desastres provocados por fortes chuvas. Entre as medidas e meios que podem ser influenciadas pela análise do gestor estadual estão: a quantidade de donativos a serem entregues e 0 possível ingresso em programas sociais e habitacionais por parte das famílias atingidas, os recursos a serem empregados para o restabelecimento de serviços essenciais e de recuperação e quais serão esses serviços, entre outros. Nesse cenário, ações de preparação visando otimizar as atividades de 
resposta, bem como a promoção de uma rápida e efetiva mobilização de recursos para o restabelecimento da normalidade, torna-se o fator primordial na padronização de procedimentos. (BRASIL, 2016).

$\mathrm{Na}$ tabela a seguir são observados os materiais de ajuda humanitária entregues às pessoas atingidas pelas chuvas que acometeram a região da Mata Sul de Pernambuco em meados de 2017, os quais somaram mais de 250.000 itens entregues.

Quadro 4: Quantitativo dos materiais entregues no desastre de 2017 (Operação Prontidão).

\begin{tabular}{|l|c|c|c|}
\hline \multirow{2}{*}{\multicolumn{1}{|c|}{ Material / Kit }} & \multicolumn{2}{|c|}{ Origem dos Recursos } & \multirow{2}{*}{$\begin{array}{c}\text { Total de } \\
\text { Recursos }\end{array}$} \\
\cline { 2 - 3 } & $\begin{array}{c}\text { Governo Federal e/ou } \\
\text { Estadual }\end{array}$ & Doações & \\
\hline Cesta básica & 32.600 & 7.515 & 40.115 \\
Pronto consumo & 2.000 & 3.390 & 5.390 \\
Kit higiene & 7.550 & 409 & 7.959 \\
Kit limpeza & 16.550 & 1.931 & 18.481 \\
Colchão & 41.760 & 1.949 & 43.709 \\
Garrafão de Água mineral & 5.000 & 3.572 & 8.572 \\
de 20I & & & \\
Garrafa de Água mineral de & 4.100 & 18.243 & 22.343 \\
1,5I & 400 & - & 400 \\
Lona plástica 8m x 100m & 17.101 & 1.583 & 18.684 \\
Cobertor & 17.429 & 1.256 & 18.685 \\
Fronha & 14.685 & 2.668 & 17.353 \\
Lençol & 17.252 & 1.424 & 18.676 \\
Mosqueteiro & 14.345 & 2.858 & 17.203 \\
Toalha & 17.889 & 1.273 & 19.162 \\
Travesseiro & 19 & - & 19 \\
Fogão com forno & 30 & - & 30 \\
Fogão sem forno & $\mathbf{2 0 8 . 7 1 0}$ & $\mathbf{4 8 . 0 7 1}$ & $\mathbf{2 5 6 . 7 8 1}$ \\
\hline TOTAL DE ITENS & & & \\
\hline
\end{tabular}

Fonte: Relatório Anual da SEDEC-PE (2017). 
É importante destacar que durante a elaboração dos procedimentos, alguns elementos básicos deverão ser observados, como: identificação do cenário de risco e seus possíveis impactos, população vulnerável, sistema de monitoramento e alerta, metodologia de trabalho dos órgãos de defesa civil e de apoio, recursos humanos e materiais disponíveis e um plano de comunicação, os quais deverão estar presentes para que a plenitude do planejamento seja atingida. (GILL e LEAL, 2008).

A padronização de procedimentos deve contemplar as mais diversas ações e atividades previstas em um desastre, como: a forma de atendimento às ocorrências, pela Central de Operações, e seus andamentos; o critério para mensurar a real quantidade de donativos a serem solicitados; o recebimento de materiais e doações pelas defesas civis estadual e municipais; a forma de contabilizar os danos e prejuízos; a sequência de ações que as equipes estaduais de apoio deverão seguir, desde a sua saída para o município até o seu retorno, pós desastre; a sequência de ações a serem desenvolvidas pelo Gabinete de Gerenciamento de Crises (GGCRISES); o repasse de informações para a mídia; e a desmobilização das equipes e estrutura montada para a resolução da emergência. Sendo assim, é de fundamental importância que o planejamento seja elaborado por equipe multidisciplinar da defesa civil estadual, com a participação, em algumas situações, de outros órgãos estaduais e municipais. Além disso, os procedimentos deverão ser testados e divulgados entre todos os integrantes que poderão participar da resposta ao desastre para que tomem conhecimento das ações previstas.

Segundo a OSHA (2011), para que um planejamento se mantenha em evidência junto aos seus partícipes, é recomendável a realização de forma periódica de simulados e treinamentos, ou sempre que haja alguma alteração que impacte nas condições de funcionamento do que foi planejado. 


\section{CONCLUSÕES E RECOMENDAÇÕES}

Diante das numerosas ocorrências por elevadas precipitações pluviométricas registradas pelos municípios da Mata Sul de Pernambuco, com destaque para as enxurradas, torna-se perceptível à grandiosidade dos danos e prejuízos ocasionados em um cenário que apresenta características que possibilitam o surgimento e o agravamento desse tipo de adversidade.

A ocupação desordenada da região somada às características climáticas, bem como da bacia de drenagem, tornam o ambiente mais sensível e potencial à origem de desastres por fortes chuvas, podendo acarretar na existência de pessoas mortas, feridas, desabrigadas, desalojadas, edificações destruídas e danificadas, que somaram prejuízos na ordem de 46 milhões de reais em 20 anos.

Salienta-se que diante das 87 ocorrências de enxurradas, com maior poder de destruição, registradas na Mata Sul de Pernambuco entre os anos de 2000 e 2019, diversas famílias foram assistidas através de donativos e programas sociais. Só no desastre de 2017 , mais de 250.000 itens foram entregues às pessoas atingidas pelas chuvas.

Sendo assim, recomenda-se que seja implementada a padronização de procedimentos de gestão por parte da Defesa Civil Estadual para atuação junto aos municípios, trazendo critérios para se mensurar a quantidade de donativos a serem entregues, a forma de recebimento e entrega desses bens, a contabilização dos danos e prejuízos no desastre, a sequência de ações a serem desempenhadas pelas equipes em campo e no Gabinete de Crises, entre outros que tragam celeridade nas ações de resposta e preservem a integridade das pessoas que compõem a Defesa Civil Pernambuco. Além disso, a confecção e/ou atualização de protocolos já existentes, manuais e legislações, também deverão ser observados para que se evite o tratamento diferenciado para situações idênticas no ambiente sinistrado. 
Por fim, novos estudos que aprofundem questões relacionadas à padronização destas ações devem ser estimulados, com foco em uma análise sistêmica dos cenários de risco da Mata Sul do Estado, para que proporcionem soluções que permitam a celeridade nas respostas e segurança nas ações emergenciais.

\section{REFERÊNCIAS}

AMORIM, G. M; SILVA, S. R. Gerenciamento de risco de enchente: o caso

Palmares. Rev. de Engenharia e Pesquisa Aplicada, v. 2, n. 1, 2016.

BACK, Adalberto G. Política Nacional de Proteção e Defesa Civil: avanços e limites na prevenção de desastres. Rev. Agenda Política, v. 4, n. 1, jan/abr. 2016.

\section{BRASIL. Constituição da República Federativa do Brasil de 1988.}

Disponível em:

<http://www.planalto.gov.br/ccivil_03/Constituicao/Constituiçao.htm>. Acessado em: 16 mar 2018.

Instrução Normativa no $\mathbf{0 2}$, de 20 de dezembro de 2016 Estabelece procedimentos e critérios para a decretação de Situação de Emergência ou Estado de Calamidade Pública pelos Municípios, Estados e pelo Distrito Federal, e para o reconhecimento federal das situações de anormalidade decretadas pelos entes federativos e dá outras providências. Disponível em: $<$ https://www.mdr.gov.br/images/stories/ArquivosDefesaCivil/ArquivosPDF/legis lacao/Portaria-MI-2---2017--.pdf>. Acessado em: 08 abr 2020.

Lei no 12.608, de 10 de abril de 2012 - Institui a Política Nacional de Proteção e Defesa Civil - PNPDEC; dispõe sobre o Sistema Nacional de Proteção e Defesa Civil - SINPDEC e o Conselho Nacional de Proteção e Defesa Civil - CONPDEC; autoriza a criação de sistema de informações e monitoramento de desastres. Disponível em: 
<http://www.planalto.gov.br/ccivil 03/ Ato2011-2014/2012/Lei/L12608.htm>. Acessado em: 15 fev 2018.

Orientações para apoio à elaboração de planos de contingência municipais para barragens. Brasília, 2016. 33p.

Sistema Integrado de Informações sobre Desastre. Disponível em: <https://s2id.mi.gov.br/>. Acessado em: 04 maio 2020.

CASTRO, Antônio Luiz Coimbra de. Glossário de Defesa Civil. Estudos de Riscos e Medicina de Desastres. Brasília: Ministério da Integração Nacional, Secretaria de Defesa Civil, 2004.

Antônio Luiz Coimbra de. Manual de Planejamento em Defesa Civil. Brasília: Ministério da Integração Nacional, Secretaria de Defesa Civil, 2005. v. 2.

FIALHO, Edson Soares. Climatologia e desastres ambientais: a demanda dos recursos públicos após o espetáculo midiático. Rev. Tamoios, São Gonçalo (RJ), ano 09, n. 1, pag. 42- 62, jan/jun. 2013.

FREITAS, Carlos Machado de. et al. Vulnerabilidade socioambiental, redução de riscos de desastres e construção da resiliência - lições do terremoto no Haiti e das chuvas fortes na Região Serrana, Brasil. Rev. Ciência \& Saúde Coletiva, vol. 17, n. 6, jun, 2012, p. 1577-1586.

GILL, A. A; LEAL, O. L. Processo de elaboração de Plano de Emergência. In: cap. XXI. A segurança contra incêndio no Brasil. 1. ed. São Paulo: Projeto Editora, 2008. 311-332 p.

GOMES, Fabiola de Souza. et al. Importância da construção das barragens Serro Azul, Barra de Guabiraba, Igarapeba, Panelas II e Gatos em 
Pernambuco para controle de cheias no Estado. VII Congresso Brasileiro de Gestão Ambiental. Campina Grande, 2016.

IBGE. Instituto Brasileiro de Geografia e Estatística. Disponível em: $<$ https://cidades.ibge.gov.br/>. Acessado em: 07 jul 2020.

LAKATOS, Eva Maria e MARCONI, Marina de Andrade. Fundamentos de Metodologia Científica. São Paulo-SP: Atlas, 2011.

MARCONDES, Clodomir Ramos. Defesa Civil. 2. Ed. São Paulo, 2003.

MICHAELIS. Moderno Dicionário da Língua Portuguesa. Disponível em: $<$ https://michaelis.uol.com.br/moderno-portugues/busca/ >. Acessado em: 08 jul 2020.

NETO, Mauro Cerri. Aspectos jurídicos das atividades de Defesa Civil. Brasília, 2007.

OCCUPATIONAL SAFETY \& HEALTH ADMINISTRATION (OSHA). 3088. How to Plan for Workplace Emergencies and Evacuations. 2011.

PERNAMBuCO. Agência Pernambucana de Águas e Clima. Disponível em: <http://www.apac.pe.gov.br/meteorologial>. Acessado em: 08 abr 2020.

PERNAMBUCO. Secretaria Executiva de Defesa Civil. Manual de Procedimentos da Operação Inverno. 2020. Manual Técnico de Defesa Civil para respostas aos desastres provocados por intensas precipitações pluviométricas. 2019.

. Relatórios Anuais. 2010-2017. 2018.

Relatório Anual. 2017. 
. Relatório Estatístico da Gerência Operacional. 2020.

POZZER, Camila Pinheiro; COHEN, Simone Cynamon; COSTA, Francisco da Silva. $O$ marco de ação de Hyogo aplicado à gestão de risco de inundação no Brasil e em Portugal. Revista Territorium, n. 21, 2014.

SANTA CATARINA. Centro Universitário de Pesquisa e Estudos sobre Desastres. Atlas brasileiro de desastres naturais 1991 a 2010: volume Brasil. Florianópolis: CEPED, 2012.

Capacitação básica em Defesa Civil. 5. Ed. Florianópolis: CEPED, 2014. $157 \mathrm{p}$.

. Manual de Capacitação para utilização do S2ID. Módulo 1:

Registro e Reconhecimento. 1. Ed. Florianópolis:CEPED, 2020. 107p.

SÃO PAULO. Corpo de Bombeiros da Polícia Militar do Estado de São Paulo. Instrução Técnica no 16 - Plano de Emergência contra Incêndio. 2011.

SHADECK, Rafael. et al. A atuação da Secretaria Nacional de Defesa Civil (SEDEC) na gestão de riscos e resposta a desastres naturais. VI Congresso CONSAD de Gestão Pública. Brasília, 2013.

SILVA, Edinéa Alcântara de Barros e. et al. Resiliência e vulnerabilidade de cidades brasileiras: lições aprendidas com os desastres da Região Serrana do Rio de Janeiro e da Zona da Mata de Pernambuco. VI Encontro Nacional da Anppas. Belém, 2012. 